\title{
Coyuntura Crítica De Negociación EnTre El Estado De Chile Y El Pueblo-Nación MAPUCHE
}

\section{Esteban Valenzuela Van Treek ${ }^{1}$ Osvaldo Henríquez Opazo ${ }^{2}$}

\section{Resumen}

El presente estudio responde a una revisión actual del conflicto chileno-mapuche, el más antiguo entre un Estado y un pueblo indígena en América Latina, el cual se ha intensificado, desde el año 1997, con un aumento del empoderamiento indígena en favor de la autodeterminación, la demanda de reconocimiento constitucional, y la devolución de tierras y recursos para su propia política de desarrollo. La coyuntura crítica de alta conflictividad social y territorial en Chile ha polarizado las posturas de autonomía indígena con el Estado que insiste en una estrategia asistencialista y neo-productivista sin negociación política y reconocimiento plurinacional en la Constitución. Por su parte, el movimiento mapuche, que coincide en su rechazo a la política estatal chilena, muestra diversas vertientes que promueven estrategias y agendas diferentes, no siempre complementarias y sinérgicas. Los resultados obtenidos muestran que las relaciones impulsadas desde los gobiernos en función de la política asistencial, de seguridad y de participación simbólica, no han sido efectivas, y que el modelo neo-productivista, basado en la renta y el monocultivo aplicado como estrategia de desarrollo, no coincide con la cosmovisión

\footnotetext{
${ }^{1}$ Doctor en Historia U. de Valencia, Director Crea Sur, Universidad de Concepción, evalenzuelavt@gmail.com Orcid: https://orcid.org/0000-0003-1755$\underline{3309}$

2 Doctor de la Universidad Complutense de Madrid, Programa Problemas Contemporáneos en la Sociedad de la Información, Académico Universidad de Talca, osvaldo.henriquez@utalca.cl Orcid: https://orcid.org/0000-0002-3974-1047
} 
del Pueblo Mapuche. Por su parte, las diferentes agrupaciones políticas, comunitarias e identitarias mapuche, no logran coincidir con un único modelo de auto-gobierno, lo que sugiere que cualquier negociación debe ser flexible en reconocer la realidad confederal del principal pueblo-nación indígena de Chile.

Palabras claves: Mapuche, Chile, Coyuntura Crítica, Negociación, Nueva Constitución, Protesta.

\section{Introducción}

La presente investigación analiza en profundidad las relaciones entre el Estado y el pueblo-nación mapuche durante el periodo que transcurre entre el segundo gobierno de M. Bachelet (2014-2018) y el término del primer bienio del segundo gobierno de S. Piñera (2018-2019). En el artículo se describen el contexto, las principales políticas públicas, y, a través de entrevistas a actores claves, se caracterizan las organizaciones, su empoderamiento y la agenda política que desarrollan. El fundamento de esta investigación radica en la vigencia e importancia de la demanda histórica y la creciente apropiación por parte de la población del ser indígena. En este sentido, la población que se declara indígena asciende al 13\% del total país. Un 80\% de ellos se identifica con el Pueblo Mapuche y, según el Censo 2017, su distribución territorial se concentra en un $34,3 \%$ en la Región de La Araucanía, seguida por las regiones de Aysén y Los Lagos con un $28,7 \%$ y $28,2 \%$, respectivamente, y la Región de Los Ríos, con un 25,6\% (INE, 2017). Los órdenes de magnitud dejan ver la dimensión de la problemática, sin embargo, el Estado, en el siglo XXI, no ha modificado el sistema de relaciones con el Pueblo Mapuche, el que está basado en una relación Estado-individuo, en donde los individuos son los beneficiarios de la política asistencialista, y no en una relación Estado-Comunidad Política, en la cual el Pueblo Mapuche es considerado como un sujeto con derechos colectivos y políticos. Antes de la explosión social, los mapuche ya se habían movilizado el año 2018 para condenar el asesinato del joven Camilo Catrillanca, 
perpetuado por fuerzas policiales (Zamorano, 2018), reanudando e intensificando los actos de sabotaje a la industria forestal en las provincias de Arauco y Malleco. Además, distintas organizaciones se han opuesto a la reforma de la Ley Indígena, destacando que tiene un objetivo de privatización de las tierras encubierto por la vía de largos arrendamientos (Aylwin, 2019). Otros, como Aucán Wilcamán, promovían el derecho a rebelión legitima para la recuperación de tierras (El Dinamo, 2018) y también un grupo de comunidades mostraban su oposición al Acuerdo por la Paz de La Araucanía, propuesto en el año 2018, exigiendo una mayor participación política (Telesur, 2018). En tanto, el movimiento mapuche rechaza nuevas rondas de consultas intrascendentes desde el Estado para la reforma de la Ley Indígena (El Mostrador, 2019), producto del fracaso de la consulta indígena en el proceso constituyente realizado en las postrimerías del Gobierno de la Nueva Mayoría. El resultado no redundó en una negociación ni en un llamado a un proceso constituyente, ni en una propuesta de constitución plurinacional, quedando solo en una sistematización de los principios y principales demandas de los mismos (MIDESO, 2017).

Hoy, nos encontramos con el escenario de una rebelión social en Chile, en el mes de octubre del año 2019, impulsada por un movimiento popular que puja por una asamblea constituyente que permita transformaciones al Estado; un movimiento que cuestiona el modelo neoliberal financiero y extractivista, exacerbado por un cesarismo presidencial territorialmente homogeneizador; la lucha sistemática del Pueblo Mapuche durante un siglo (Mella, 2018) e intensificada desde la década del 90, en el contexto de la emergencia de la cuestión indígena en el continente (Bengoa, 2000); la insurgencia activa del pueblo-nación mapuche, convirtiéndose en el principal conflicto territorial en Chile (Foerster y Montecino, 1988; Cortez, F. Marimán, J. Molina, R. Valenzuela, E. , 2015; González y Valenzuela, 2017; Mella, 2018); y el conflicto visible en el territorio conocido como 
Wallmapu ${ }^{3}$, espacio donde se construye la idea de territorio mapuche, lo que configuraría el concepto de nación (Calduch, 1991). En el presente artículo planteamos que estos elementos de conflictividad social generalizada, un Estado débil y el surgimiento del conflicto mapuche, configuran las condiciones necesarias para que los actuales acontecimientos se conviertan en una coyuntura crítica (Mahoney, 2001), modificando sustancialmente las relaciones pre-existentes.

La evolución y las condiciones actuales del conflicto mapuche surgen de una coyuntura crítica anterior, generada en esa oportunidad por el desconocimiento del Tratado de Tapihue ${ }^{4}$. La guerra civil del año 1829, periodo en que se inicia la política de Estado, permitió mantener la ocupación de los territorios a fines del silgo XIX. En casi dos siglos, los regímenes conservadores, autoritarios y centralistas que prosiguieron no han vuelto a negociar con el Pueblo-Nación Mapuche en su diversidad, ni han emprendido un proceso real de reconocimiento que lleve a políticas de mayor autonomía o a la creación de una región plurinacional y multicultural (Comisión para la Descentralización, 2014). De este modo, a diferencia de avances en otros países latinoamericanos, respecto de la autonomía y representación (Marimán, 2012), el proceso de homogeneización como política de Estado no ha permitido transferir potestades territoriales. No se ha otorgado reconocimiento y tampoco se ha promovido la creación de instituciones -como, por ejemplo, una universidad mapuche- que fomenten la cultura y el desarrollo de su lengua. Además, las políticas basadas en la consulta reglada por el DS. N66: 2014, no han podido incidir o disminuir el conflicto. Incluso, han demostrado su inoperancia producto del proceso de minorización, que

${ }^{3}$ El territorio Wallmapu se extiende desde la Provincia de Arauco en la Región del Biobío hasta la zona costera de la Región de Los Lagos, con una extensión lineal de $600 \mathrm{~km}$. aproximadamente.

${ }^{4}$ El Tratado de Tapihue fue firmado por el presidente Ramón Freire el año 1825. Freire era oriundo de Concepción y de tendencia federalista. 
no acepta a los mapuche como un sujeto político, un pueblo-nación originario con derechos ancestrales y colectivos (Boitano, 2014).

Con la nueva democracia y sin el reconocimiento político del Pueblo Mapuche, se produjeron avances parciales. Algunos gobiernos se enfocaron en la creación de organismos burocráticos y programas estatales de carácter asistencial, entre ellos, la Comisión Nacional Indígena (CONADI) y su fondo de tierras. Así también se efectuaron algunos gestos simbólicos de perdón histórico sin transformaciones políticas, que se traslaparon con políticas de represión y el uso de la Ley de Seguridad Interior del Estado (La Tercera, 2017) debido a los sabotajes a la industria forestal, incendios de bosques y camiones, junto con ocupación de tierras en manos de latifundistas y empresas. El Gobierno actual continuó con la política imperante. Se instauró una administración del Estado bajo el paradigma del duopolio centralista y oligárquico, y el temor a la profundización democrática del grueso de la clase política de centro izquierda, negando poder político y financiero a los territorios, así como autonomía a las etnias originarias. Dado lo anterior, es posible señalar que la política chilena sobre la cuestión indígena se ha caracterizado más por la homogeneización, minimización y segregación. Todas más cercanas al estilo de las políticas aplicadas por Turquía con el pueblo kurdo, que a las políticas de reconocimiento de países como Dinamarca y Canadá con los inuit, en Nueva Zelandia con los maoris o los Escandinavos con los samis.

\section{De la consulta indígena constituyente y el regreso del asistencialismo productivista}

Las razones del mayoritario rechazo de los mapuche a nuevos procesos de consulta en el gobierno de Chile Vamos, es resultado del fracaso de decenas de encuentros y hojas escritas, millones de pesos en gasto público, expectativas no cumplidas y múltiples consultas constituyentes realizadas entre los años 2014 y 2017, además de un diálogo político sin resultados concretos bajo la articulación del 
Obispo Vargas. Así también, el sentirse presa de manipuladores y operadores políticos en los gobiernos previos, en consultas y diálogos banalizados en la rutina estatal de la participación simbólica, sin negociación ni consecuencias (Arnstein, 1969). Todo esto complementado con políticas de incentivos inversos, consistente en el par "política asistencial y la acción policial", o el proceso de militarización del conflicto mapuche (González, 2019), implementados por los últimos ministros del interior y seguridad pública.

A pocos días de asumido el segundo gobierno de Chile Vamos, "funcionarios del Ministerio de Desarrollo Social desecharon miles de documentos que habían preparado académicos de la Universidad de Chile con las propuestas y su sistematización final, por región, del proceso constituyente indígena" (anónimo, entrevista, 19 de julio de 2018). Actos como estos descartan e inhabilitan un masivo proceso de auto consulta y debate que generó líneas explícitas en favor del reconocimiento constitucional, derechos ancestrales, lengua, representación política, autonomía y un desarrollo alternativo al extractivismo forestal. La nueva estrategia del Ministerio de Desarrollo Social se basa en retomar el enfoque productivista y no en las relaciones de derecho (Valenzuela, 2018). El proceso desechado había sido útil para generar una sistematización de propuestas que resaltaba el interés de los mapuche de la Región Metropolitana por participar en el parlamento, acceder a becas y tener reconocimiento cultural, en complemento al énfasis de los mapuche del territorio Wallmapu, cuyo objetivo es la de construir un poder político territorial, autogobierno y apoyo agrícola.

\section{La universidad mapuche para potenciar la lengua y la cultura}

En indicadores como el Índice de Desarrollo Regional (IDERE, 2019), la Región de La Araucanía aparece muy rezagada en servicios, empleo e inversión -todo de responsabilidad pública- y presenta resultados favorables en medio ambiente, salud y seguridad ciudadana porque, a pesar de los "delitos de sabotaje", la región se encuentra entre las tres 
más seguras del país, siguiendo la tendencia de América Latina, donde a más alta población indígena hay menos robos, violaciones y asesinatos. Estas ventajas del territorio indígena no están siendo relevadas en los libros de la ortodoxia de la Escuela de Economía de Chicago. Sin embargo, se han ido dando pasos incipientes para recuperar la lengua. Entre ellos y, a modo de ejemplo, la incorporación de señalética bilingüe en los servicios públicos y la salud multicultural. Por otro lado, no hay mayores avances en la creación de centros bilingües en comunas indígenas o la promoción de un canal público mapuche, así como tampoco han tomado en consideración las propuestas de los intelectuales indígenas sobre la creación de la universidad mapuche, la que fue asumida por el partido Federación Regionalista Verde Social (FREVS), en el cual participa un segmento del movimiento político Wallmapuwen.

El proyecto consiste en la creación de tres universidades indígenas. Una en la provincia del Loa, para andinos, otra en la provincia del Huasco, para diaguitas, y otra en la provincia de Malleco, para estudiantes mapuche, al ubicarse en el centro del eje Arauco-Cautín. Dirigentes políticos del FREVS, como Esteban Velásquez y Jaime Mulet $^{5}$, proponen una modificación a la ley sobre universidades estatales para promover la creación de universidades indígenas interculturales. Velázquez" (2018) señala que "El proyecto de ley, pretende que en estas universidades se acoja y se valore la cosmovisión de nuestros pueblos que hoy día, si bien están reconocidos en el marco de los derechos humanos, no han sido considerados de forma vigorosa para formar en su cultura, y a nuestro juicio, para ello, efectivamente tienen que haber centros de educación superior donde se desarrolle investigación y extensión hecha por y para nuestros pueblos indígenas, pues serán las universidades, sus alumnos y comunidad las que van a dar origen a una nueva mirada y un reconocimiento a los pueblos

5 A la fecha, diputado por la Región de Atacama y presidente del FREVS.

${ }^{6}$ A la fecha, Esteban Velázquez es diputado por la Región de Antofagasta. 
originarios"7. Los parlamentarios del FREVS apelan a la obligación del Estado de Chile en el marco del Convenio No169 de la OIT, firmado en el año 2008, que reconoce, promueve y protege los derechos de los pueblos originarios. También se establece en el Convenio la obligación del Estado de promover las instituciones de enseñanza superior indígenas, de manera que tengan todos los pueblos y todas las naciones en el país, sus propias universidades, propiciando la política de interculturalidad.

\section{El modelo asistencial neo-productivista: arrendamiento de tierras, asfalto, agua potable y el avellano europeo}

El territorio mapuche tuvo una economía próspera hasta 1850, basada en la ganadería de auquénidos y el comercio en las fronteras con incas, españoles y chilenos. Este modelo productivo fue fracturado por el gran latifundio monoproductor. En el siglo XIX fue el trigo y, desde mediados del siglo XX, el sector forestal. La estrategia predominante del segundo gobierno de Sebastián Piñera ha sido la empresarización del Pueblo Mapuche, ejecutada por el exministro de Desarrollo Social, Alfredo Moreno (El Mostrador, 2018), que buscó -en vanosimplificar el conflicto con una salida productivo-capitalista como estrategia central del desarrollo. A modo de ejemplo, la introducción del avellano europeo con buen precio en los mercados internacionales. Para eso, el Gobierno buscó con insistencia un acuerdo para incorporar el modelo rentista a través del arrendamiento a largo plazo de sus tierras comunitarias: el mismo modelo en que el Estado subsidió a las grandes empresas forestales en dictadura, y que tuvo como consecuencia que los mapuche vieran empobrecido su entorno, convirtiendo el centro sur costero en la zona más pobre de Chile y de mayor conflictividad (Cortez et al, 2015). Precisamente, este modelo fue rechazado por las comunidades, proceso que coincide con la salida del ministro Moreno de la cartera a mediados del año 2019.

\footnotetext{
${ }^{7}$ Discurso realizado en el marco de la presentación del proyecto que impulsa la creación de universidades indígenas interculturales.
} 
El palacio de La Moneda, la casa de Gobierno, fue visitado por una delegación mapuche liderada por Diego Ancalao, intelectual mapuche, acompañado por lonkos de la zona nagche de Purén, ubicada en la provincia de Malleco. En esa ocasión se reunieron con el ministro Alfredo Moreno con el objetivo de solicitar apoyo para realizar programas de fortalecimiento al capital social indígena y de reconocimiento, como lo obrado en Nueva Zelandia con la etnia maorí. El ministro, en esa oportunidad, insistió en la tesis de que el subdesarrollo surge de la propiedad colectiva de la tierra y profetizó que la prosperidad se basaba en el arrendamiento productivo de la tierra y la necesidad de incorporarse a un modelo capitalista. Ancalao relata: "Moreno nos planteó que, así como él era un próspero agricultor de arándanos y berries en Maule y Nuble, los mapuche debían aliarse con buenos productores para su prosperidad" (Diego Ancalao, entrevista, 6 de mayo de 2018). No hubo en sus palabras, comprensión de la demanda histórica y política del Pueblo-Nación Mapuche, entre ellas, reconocimiento, plurinacionalidad, región autónoma, universidad indígena, ni menos, planes y rentas regionales que aseguren por ley los recursos estructurales que permitan la disminución de las inequidades territoriales para Wallmapu.

En el proceso de la consulta indígena constituyente de 2015, los mapuche relevaron e insistieron en su propio modelo de desarrollo, tal como lo evidencian las actas levantadas en el proceso. "El Estado debe reconocer y resguardar la existencia de distintas formas de concebir el desarrollo social y económico, lo cual también respondería al principio de interculturalidad" (Ministerio de Desarrollo Social, 2017, p.17). Lo anterior evidencia la contradicción entre el modelo neo-productivista y las prácticas culturales indígenas y su vinculación con el territorio. La contraposición de visiones sobre el modelo de desarrollo ha estado en la base del conflicto entre el Estado chileno y el Pueblo Mapuche. Como indica el propio informe del proceso constituyente, las comunidades indígenas deben decidir sobre un modelo de desarrollo 
basado en la cosmovisión de sus pueblos (Ministerio de Desarrollo Social, 2017).

En síntesis, la estrategia neo-productivista, basada en el arrendamiento de tierras y la producción de monocultivos, se convirtió en un emblema, en una suerte de choque de civilizaciones o de paradigmas entre quienes sueñan con grandes plantaciones forestales o frutales que, con tractores gigantes, llevan la cosecha a un packing, donde un grupo de ordenadas temporeras que laboran silentes en una cinta transportadora, empacan raudas para que luego grandes containers salgan por un mega puerto al Asia; versus los peumas -sueños, visiones- del movimiento mapuche que, en su diversidad confederal, aspira a rescatar y recrear en códigos de hoy un territorio intercultural, sustentable, con emprendimientos diversos, donde florezca el bosque nativo y las plantas medicinales que sanan a buena parte de Chile, la ciencia, los servicios avanzados, las universidades y la cultura de un pueblo sabio (Mella, 2018).

La ausencia de negociación: omisión lesiva estatal, regional e internacional y debilitamiento de representación mapuche incluyendo la destrucción del partido Wallmapuwen

El actor nacional que reaccionó a la falta de negociación fue la Comisión Justicia y Paz en el año 2016, haciendo un llamado explícito a la "santidad de negociar con el Pueblo Mapuche" (Conferencia Episcopal, 2017). Lo anterior no se tradujo en un llamado explícito del Papa Francisco a una negociación en su visita a Chile el 2017, ni tampoco fue acogida por la Conferencia Episcopal como política eclesiástica. Sin embargo, sí han participado a través del obispado de Temuco, quien coordinó el diálogo en la Región de La Araucanía el año $2016^{8}$.

\footnotetext{
${ }^{8}$ Cuyo resultado fue solo en una lista de problemas de diversa envergadura, que no incluye las demandas políticas levantadas durante el proceso inconcluso de la nueva Constitución.
} 
Con el mismo sentido de mantener una participación activa, la presidenta de Justicia y Paz, Carmen Donoso, junto con jesuitas de la comuna de Tirúa, promovió en la primavera del año 2018 en el Obispado de Concepción, un diálogo franco y áspero entre el ministro Moreno, dirigentes mapuche y la intelectual Natalia Caniguán. Esta última le recordó a la autoridad que "la tierra, para los mapuche, no es una cosa a la cual sacarle renta" (Natalia Caniguán, exposición "Cómo construimos paz en el wallmapu", 13 de agosto del 2018). El diagnóstico gubernamental, a la fecha, era que la mayor falencia está en lo social y, por ello, la petición presidencial se configuró como una alerta para el Ministro de Desarrollo Social, pues graficaría lo descrito hace meses ya desde el oficialismo y parlamentarios de la zona: "Mucho anuncio, poca ejecución" (Leighton, 2019). El ministro no se atrevió a replicar, a propósito del conflicto chileno-mapuche, lo que él vivió en el proceso de negociación entre las FARC y el Gobierno de Colombia. Sin embargo, se optó por una política pública de continuidad y de planes inocuos: llamar a dialogar a los pacíficos -la eterna manipulación decimonónica entre "indios buenos" e "indios malos"-; mejorar políticas de escasa relevancia; y acelerar la marcha del Estado. Como consecuencia, el Gobierno no pudo superar los diálogos intrascendentes y las consultas rutinizadas, siendo algunas de ellas desechadas, tales como los informes del sueño constituyente.

La ausencia de negociación ha residido principalmente en la falta de voluntad política de los distintos gobiernos y la desidia del Congreso Nacional y de los consejos regionales, dominados por los partidos políticos nacionales. La Iglesia Católica tampoco ha tomado la posta, en medio del descrédito por encubrimientos en escándalos sexuales. A su vez, se puede observar también una ausencia de organismos internacionales o de una alianza de países, como el esfuerzo de Noruega y Cuba en los acuerdos de paz de Colombia y Venezuela. No se evidencia mayor involucramiento de organismos internacionales en los últimos años, aun cuando la Comisión Interamericana de Derechos Humanos ha recibido denuncias tanto por usurpación de tierras 
mapuche, como por las duras condenas definidas por la aplicación de la Ley Antiterrorista en el año 2014 en el caso del machi Celestino Córdoba y la prolongación del proceso de militarización del conflicto con vulneración de derechos de niños, niñas y jóvenes.

Otro factor que no ha permitido configurar una negociación ha sido la dispersión política y la multiplicidad de agendas de las comunidades mapuche. Si bien, en general, apoyan el proceso de devolución de tierras y el reconocimiento constitucional (Marimán, 2012; González y Valenzuela, 2017), no hay gran alineación respecto a la necesidad de diálogo político institucional. La historia señala que, tanto en la guerra de Arauco contra los españoles, entre los años 1550 y 1790, como también en el proceso de resistencia a la ocupación de las tierras por el ejército chileno, a fines del siglo XIX, los mapuche hicieron aillarehues o acuerdos entre diferentes lof comunitarios, coincidiendo en delegaciones que les representaron en parlamentos con los españoles e intentos fallidos de acuerdos con el Estado chileno (Foerster y Montecino, 1988; Gundermann, 2003; Mella, 2018). Es decir, hoy no promueven acuerdos del tipo confederal, aunque sí reivindican un movimiento territorial autonomista y plural. A pesar de la dispersión, la estrategia de desobediencia al Estado ha tenido relativo éxito, dada la detención de la expansión forestal, al menos en la provincia de Arauco, y la mayor devolución de tierras conseguida desde la reforma agraria de 1965-73 (Cortez et al, 2015). Una característica ancestral del Pueblo Mapuche, dada su configuración confederal, es la multiplicidad de liderazgos, que ha tenido diversos efectos: uno de los favorables ha sido la aplicación de una diversidad de enfoques y estrategias con resultados sinérgicos que han logrado una "mapuchinización” parcial de Chile (Cayuqueo, 2014). Un rasgo típico en las movilizaciones actuales, incluidas las de octubre del año 2019, es el uso masivo de la bandera mapuche, pese a que no han logrado forzar la negociación política entre el Estado y el Pueblo-Nación Mapuche, que probablemente ocurra en el proceso de cambio institucional producto de la coyuntura crítica. 
La dispersión de agendas y pluralidad del movimiento se da en diversos grupos. Ejemplo de ello son la emblemática comunidad de Temucuicui ${ }^{9}$; la Coordinadora Arauco Malleco (CAM), que lidera desde 1997 la estrategia de reivindicación (Werken, 2019) a través del sabotaje a la industria forestal y que es liderada por Héctor Llaitul desde el lago Lleu-Lleu; y el Consejo de Todas las Tierras, que emergió en 1992 junto con la celebración de los 500 años de la llegada de los españoles a América. Liderada por Aucán Huilcamán, el Consejo de Todas las Tierras promueve la autodeterminación sin especificar sus formas ni procesos.

Estas organizaciones conviven con otros grupos definidos como identitarios que, más allá del nacionalismo pan-mapuche, reivindican, por ejemplo, a los pehuenches de la montaña, cuyos referentes son Pascual Levi y la familia Quiltramán en el Alto Biobío; los lafkenches de la costa, liderados por Adolfo Millabur desde Tirúa, quienes han ido re-etnificando a muchos huilliches (mapuche del sur) como lafkenches por la ley que les otorga prioridad en las explotación del borde costero, expandiéndose hasta Aysén (Espinoza, 2016); o la federación huilliche, que congrega las comunidades de la isla de Chiloé.

Por su parte, en el contexto político electoral, se identifica el partido Wallmapuwen, inspirado por José Marimán, con el propósito de empoderarse en la Región de La Araucanía ampliando el territorio del Wallmapu. Sus objetivos eran recuperar su lengua y el fortalecimiento económico y político, controlando -al menos- la mitad del consejo regional. Con posterioridad a su disolución, forzada por el cambio de legislación, el movimiento se dividió en la facción culturalista, del académico Víctor Nanqil, y la facción regionalista, de Ignacio Astete, Danko Marimán e Isabel Canet. Esta última facción se integró al partido Federación Regionalista Verde Social (FRVS).

\footnotetext{
${ }^{9}$ La comunidad Temucuicui se negó a participar en el censo del año 2017 y, además, es el lugar en el que ocurrió el asesinato de Camilo Catrillanca, el año 2018.
} 


\section{Trabas y dificultades legales inviabilizan la representación política mapuche}

El Wallmapuwen se forjó como el partido de "los integrantes del Wallmapu" o "compatriotas del país mapuche" y fue la concreción partidaria de la lucha del Pueblo Mapuche por tener un espacio de incidencia político institucional en la Región de La Araucanía. Aprovechando la ventana que se produjo para la constitución de partidos regionales, publicó en El Diario Oficial su extracto de constitución el 30 de octubre de 2015, inscribiéndose el 9 de junio de 2016 con escrituras en una notaría de la ciudad de Temuco y con domicilio establecido en esa ciudad. En el año 2017 se modifica la ley y se eliminan los partidos regionales, exigiendo la existencia mínima de tres regiones contiguas. En este caso, el Wallmapuwen solo tenía existencia en una región y tuvo que transformarse en un movimiento que se hizo parte de las corrientes regionalistas. En su ideario, la figura del autonomismo es fundamental, ante lo cual, se asume su asociación a las luchas de reivindicación territorial. Al incorporar en el lema el concepto Kizugünetuafiyñ Taĩ̃ Wallmapu ("amigos del bienestar y la democracia"), hace parte de su proyecto la noción de "bienestar", asociado a la relación armónica del ser humano con la naturaleza. Estos principios lo constituyen en un referente mapuche, político y cultural, con raíces profundamente ligadas a la naturaleza y al cuidado y uso racional de ésta como parte de su imaginario. Es posible observar en sus planteamientos parte importante de las reivindicaciones del movimiento mapuche, al tener como eje la oposición a los impactos sociales y ambientales de proyectos extractivistas forestales e hidroeléctricos (Segura, 2017). Wallmapuwen, durante su existencia, tuvo cierto impacto electoral al obtener en las elecciones municipales $6 \%$ en promedio en las ocho comunas donde se presentó, eligiendo una concejala, Sara Huenchupil, en el municipio de Galvarino y estando a décimas en otras tres comunas. Estos logros podrían ser meritorios si se considera el poder histórico de los partidos 
nacionales que representan a la derecha y la Nueva Mayoría en esta región.

En el plano político, en las elecciones parlamentarias del año 2017, fue electo senador por la Democracia Cristiana, Francisco Huenchumilla, de origen mapuche, y también la diaguita Yasna Provoste. En la Cámara de Diputados, por su parte, se integraron dos diputados del Comité FREVS -Esteban Velásquez y René Alinco- y las diputadas Emilia Nuyado y Aracely Leuquén. Por primera vez, ellos conforman un grupo de parlamentarios de origen indígena electos sin acción de discriminación positiva.

En el contexto latinoamericano, la participación política es liderada por Bolivia con un tercio del Congreso, país donde no ha habido un partido nacional indígena equivalente a la hegemonía quechua-aymara del Movimiento al Socialismo (MAS), que ha dejado en segundo plano las autonomías indígenas campesinas ya que domina el Estado y los municipios (Herrera, 2019). Más atrás se ubican Guatemala con un $12 \%$, y Perú y Ecuador en torno al 7\%, donde el partido Pachacuti ha tenido protagonismo (García, 2018). Como se puede observar en la Tabla N ${ }^{\circ} 1$, Chile, por su parte, cuenta con una participación en torno al 3\%, de forma equivalente a la participación en México y Nicaragua. El pueblo kuna, en el caso de Panamá, se concentra en sus propios territorios, de características autónomas, en la Comarca de San Blas, desde la guerra civil de los 1930s (Morcillo, 2013). La base en Panamá es la comunidad, que se reúne en asambleas para los asuntos claves. "En la Casa del Congreso se realiza la democracia participativa kuna. Esta tradición viene de los antepasados y si desapareciera, los kuna quedaríamos sin corazón, sin nación” (Bartolomé \& Barabas, 2004, p. 10). Esta descripción se acerca más al lof mapuche y el autogobierno que, en la práctica, han recuperado en Temucuicui, Ralco, TirúaLleulleu y lago Budi, entre otros territorios. 
Tabla N $\mathbf{N}^{\mathbf{0}}$ : Parlamentarios indígenas y porcentaje sobre el total de asientos parlamentarios en siete países

\begin{tabular}{lccc}
\hline \multicolumn{1}{c}{ País } & Periodo & $\begin{array}{c}\text { Parlamentarios } \\
\text { indígenas }\end{array}$ & $\begin{array}{c}\text { Porcentaje } \\
\text { parlamentarios } \\
\text { indígenas }\end{array}$ \\
\hline México & $2012-2015$ & 14 & $3 \%$ \\
Guatemala & $\mathbf{2 0 1 2 - 2 0 1 6}$ & $\mathbf{1 9}$ & $\mathbf{1 2 \%}$ \\
Nicaragua & $2006-2009$ & 3 & $3.3 \%$ \\
Ecuador & $2009-2013$ & 7 & $5.6 \%$ \\
Perú & $2011-2016$ & 9 & $7 \%$ \\
Bolivia & $\mathbf{2 0 0 9 - 2 0 1 5}$ & $\mathbf{4 1}$ & $\mathbf{3 1 . 5 \%}$ \\
Chile & $2018-2022$ & 6 & $2.7 \%$ \\
\hline
\end{tabular}

Fuente: Elaboración propia en base a informe PNUD (2015)

El sistema electoral y de representación política en Chile intensifica la ausencia de representación política cohesionada. Las comunidades indígenas carecen de escaños garantizados en el Congreso o sistemas especiales de representación parlamentaria, y su participación en instancias políticas convencionales ha sido escasa (Fundación Aitue, 2014). Ello se observa en cinco liderazgos. Aucán Huilcamán, del Consejo de Todas las Tierras, obtuvo una buena votación en la misma elección de senadores de Huenchumilla ${ }^{10}$. Sin embargo, la propuesta ${ }^{11}$ del partido Wallmapuwen diseñada por Marimán, fue asumida por la comisión presidencial para la descentralización el año 2014. Por su

\footnotetext{
10 Ambos líderes no coinciden con Marimán, que a fines de los 2000, en el marco de sus estudios de doctorado en ciencia política en Galicia, documentó cómo las naciones subalternas se empoderaban en un territorio específico, desde los kuna y misquito en América Latina (Panamá y Nicaragua), hasta los inuit y samis en la zona ártica, y vascos y catalanes en España.

11 La propuesta asumida por la Comisión de Descentralización consiste en la creación de una Región Wallmapu, con un 40\% de representación mapuche asegurada por 20 años, estatuto de autonomía plurinacional, bilingüe, con promoción del mapudungun y plebiscitos para que comunas aledañas de las regiones del Biobío y Los Ríos se sumen a la misma.
} 
parte, Héctor Llaitul, con un discurso maximalista de nación mapuche y socialismo, tampoco valoró la propuesta de Marimán.

Es posible observar en el proceso de consulta constituyente mapuche, la existencia de diferencias entre grupos mapuche, organizaciones y agendas (ver Tabla N²). Los del sur-provincia de Arauco y Región de La Araucanía- se presentan con un claro énfasis territorialista, que propone la constitución de un territorio y un modelo de desarrollo alternativo y autónomo. Los mapuche del Gran Santiago, por su parte, piden derechos culturales (identidad en la gran ciudad) y representación política por cuotas en municipios, gobiernos regionales y el Congreso Nacional, sobre todo en la zona sur de la Región Metropolitana. Los lafkenches, liderados por el alcalde de Tirúa, Adolfo Millabur, han logrado convertir a la identidad lafkenche en un referente de crecimiento por toda la costa. Uno de sus principales líderes explica el proyecto de esta forma: "no quiero depender de una burocracia desde Temuco, sea chilena o mapuche, lo nuestro es confederal e identitario según nuestros ancestros, por algo nos llaman los habitantes de la costa" (Adolfo Millabur, entrevista, 16 de octubre de 2018). 


\section{Tabla N²: Principales organizaciones y agendas del movimiento mapuche}

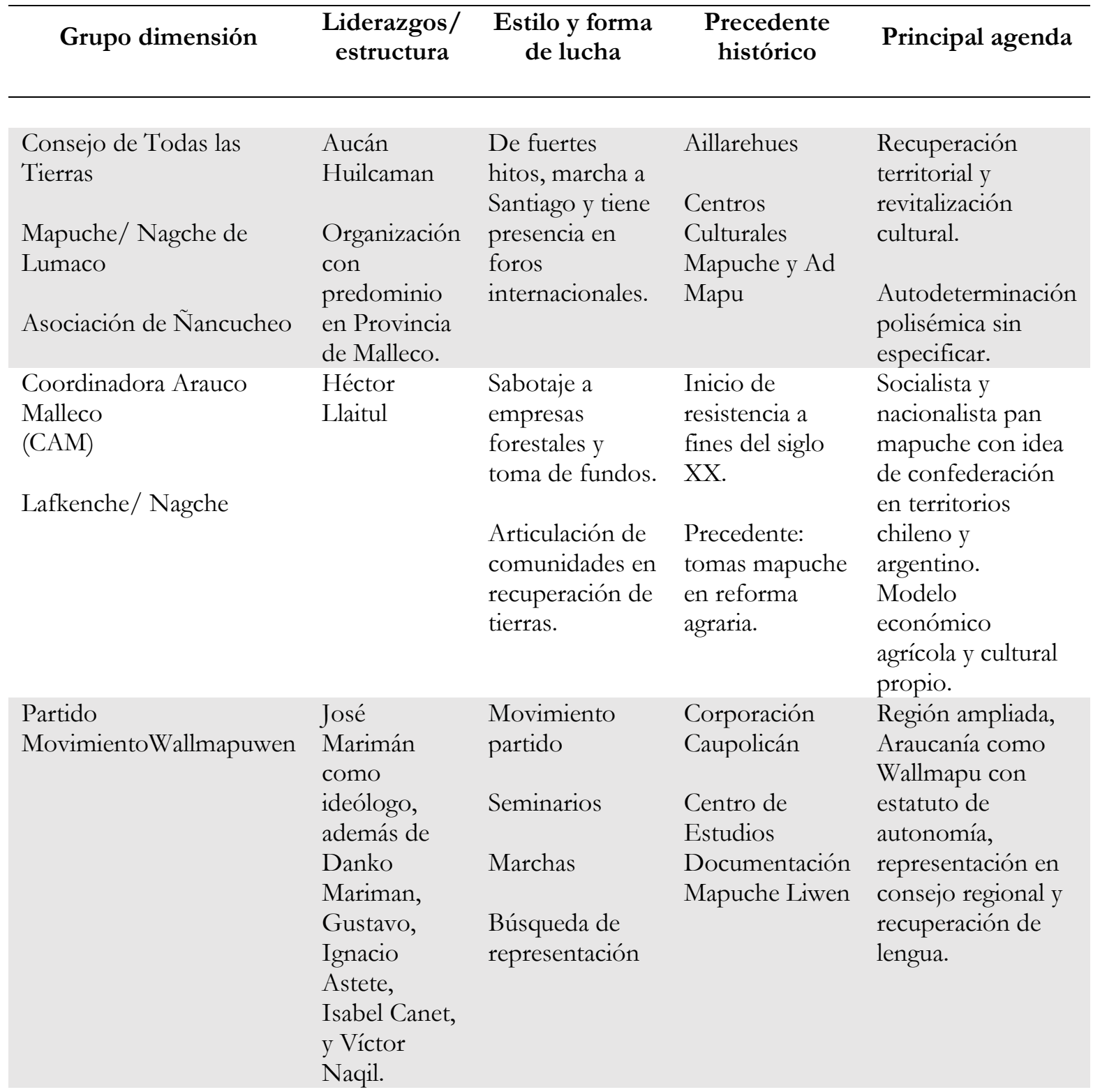




\begin{tabular}{|c|c|c|c|c|}
\hline $\begin{array}{l}\text { AMCAM (Asociación de } \\
\text { Municipalidades } \\
\text { con Alcalde Mapuche) }\end{array}$ & $\begin{array}{l}\text { Juan Carlos } \\
\text { Reinao, } \\
\text { Adolfo } \\
\text { Millabur, } \\
\text { Luis Huirilef, } \\
\text { Manuel } \\
\text { Painequeo, } \\
\text { Nibaldo } \\
\text { Piñaleo, Juan } \\
\text { Paillafil, Abel } \\
\text { Painefilo, } \\
\text { Alejandro } \\
\text { Huala y } \\
\text { Ramona } \\
\text { Reyes } \\
\text { Painequeo }\end{array}$ & $\begin{array}{l}\text { Articulación } \\
\text { Lobby desde la } \\
\text { institucionalidad } \\
\text { Pactos locales y } \\
\text { acuerdos con } \\
\text { empresas, en } \\
\text { algunos casos. }\end{array}$ & $\begin{array}{l}\text { Pegun Dungun } \\
\text { Identidad } \\
\text { Territorial } \\
\text { Lafkenche } \\
\text { Coordinadora } \\
\text { Arauco Malleco }\end{array}$ & $\begin{array}{l}\text { Derechos } \\
\text { colectivos, } \\
\text { recursos } \\
\text { adicionales, } \\
\text { interculturalidad y } \\
\text { pertinencia cultural } \\
\text { en gestión. }\end{array}$ \\
\hline \multirow[t]{2}{*}{ Identidad lafkenche } & $\begin{array}{l}\text { Adolfo } \\
\text { Millabur, } \\
\text { José Linco, } \\
\text { Iván Carilao }\end{array}$ & $\begin{array}{l}\text { Recuperación } \\
\text { potestades } \\
\text { borde costero } \\
\text { indígena }\end{array}$ & $\begin{array}{l}\text { Comunidades y } \\
\text { asociaciones } \\
\text { mapuche de } \\
\text { Arauco a } \\
\text { Chiloé }\end{array}$ & $\begin{array}{l}\text { Identidad } \\
\text { territorial } \\
\text { Nación mapuche } \\
\text { confederada }\end{array}$ \\
\hline & & $\begin{array}{l}\text { Devolución de } \\
\text { recursos }\end{array}$ & Pegun Dungun & $\begin{array}{l}\text { Devolución costa } \\
\text { de mar y lagos a } \\
\text { mapuche en toda } \\
\text { la Patagonia. }\end{array}$ \\
\hline $\begin{array}{l}\text { Comunidad } \\
\text { Temucuicui }\end{array}$ & $\begin{array}{l}\text { Varios } \\
\text { rotativos }\end{array}$ & $\begin{array}{l}\text { Conflicto } \\
\text { sostenido con el } \\
\text { Estado Chileno }\end{array}$ & $\begin{array}{l}\text { Lof tradicional y } \\
\text { rehues }\end{array}$ & $\begin{array}{l}\text { Poder de los lof } \\
\text { mapuche } \\
\text { autónomos como } \\
\text { municipios } \\
\text { indígenas. }\end{array}$ \\
\hline
\end{tabular}

Fuente: Elaboración propia con aportes de Magaly Mella (Universidad del Biobío) y Jaime González (U. Autónoma-Talca). 


\section{Los alcaldes mapuche y su creciente poder territorial}

El poder territorial de los alcaldes mapuche será el eje de las futuras negociaciones políticas. El municipio es lo que ha representado el poder territorial y ha permitido el empoderamiento indígena en América Latina (Espinoza, 2014), tal como ocurrió con los mayas en Guatemala, a través de comités cívicos o usando los partidos tradicionales de moda (Bastos y Camus, 2004). O en Chiapas, con aliados al movimiento zapatista en municipios oficiales o paralelos, como los caracoles. Los aymara no hablan mucho de autonomía porque dominan los municipios del altiplano que comparten el triángulo peruano, boliviano y chileno (Albó, 2000; González y Valenzuela, 2017), los quechuas han ido avanzando en Bolivia en el poder formal y local de manera hegemónica (Herrera, 2019), y en Chile se valora el buen gobierno del mapuche. Juan Carlos Reinao y la AMCAM combinan el apoyo a su pueblo-nación -cuando se le criminaliza por las protestas y sabotajes, piden consultas vinculantescon la negociación por leyes y proyectos, y han obligado a las mega empresas a compartir valor con las comunidades, como el caso de los parques eólicos de Renaico, que aportan un millón de dólares anuales al pequeño municipio versus los veinte dólares de las mega celulosas a la municipalidad de Arauco, liderada por los magnates de Santiago. Un funcionario municipal de Renaico es claro al explicar la complementariedad de estrategias de reivindicación política: "el movimiento mapuche opera en el escuchar de empresas pactistas que saben que, más allá del alcalde de Renaico, el educado médico Reinao, se encuentra la AMCAM y todo el movimiento mapuche que puede sabotear el parque eólico si no hay respeto a la comunidad y no se 
comparte el valor de manera estructural" (Entrevista a directivo municipal de Renaico, 23 de octubre 2018) ${ }^{12}$.

Natalia Canihuán (2015) cuenta con un valioso libro sobre las trayectorias de los alcaldes mapuche, donde muestra el paso desde lo estudiantil, al poder político y su expansión. Entre los casos descritos, se encuentran Adolfo Millabur y Juan Carlos Reinao -el actual presidente de la AMCAM- quienes se politizaron durante sus estudios en Concepción. Reinao, por ejemplo, dejó la carrera de Derecho y se convirtió en médico en Cuba, para lograr - con su buena gestión- dos tercios de los votos en la elección en Renaico. En los noventas, solo hubo dos alcaldes de origen mapuche. Hoy, los alcaldes son una decena, desde la Región del Biobío a Paillaco, en la Región de Los Ríos, donde gobierna Ramona Reyes Painequeo.

\section{Conclusiones: La posible apertura plurinacional en el momento constituyente de Chile}

La permanencia del conflicto mapuche en el tiempo y el movimiento social actual en Chile, se presentan como eventos claves para la conformación de una coyuntura crítica que desembocará en un proceso constituyente, cuyo centro es la cuestión territorial, la equidad, el reconocimiento de los indígenas basado en su empoderamiento y el desarrollo de modelos sustentables. Esto debe ocurrir en un proceso de negociación directa en su diversidad, planteándose como un cambio en la relación Estado y la Nación Mapuche, como ocurrió por última vez hace casi dos siglos con el Tratado de Tapihue. La negociación política en el marco de una nueva relación entre el Estado y la nación mapuche, puede ser liderada por la asociación de alcaldes mapuche, reconociéndose en ellos un poder político emergente. El proceso debe

\footnotetext{
${ }^{12} \mathrm{El}$ directivo de carrera enfatiza la admiración transversal por Reinao y el auge de Renaico en manos del alcalde mapuche por su integridad, inteligencia y capacidad de "obligar a las empresas a pagar un verdadero royalty territorial".
} 
ser acompañado de veedores internacionales -cuyo resultado es el reconocimiento constitucional de la plurinacionalidad- y concretar fórmulas para implementar un proceso de devolución de poder, territorio y recursos. Un cambio en la relación entre el Estado y la nación mapuche significa poner el foco en el reconocimiento del Pueblo Mapuche como un sujeto político y sus derechos colectivos a la autonomía y autogobierno expresados en un territorio característico.

En la cuestión material, sin duda, el cambio del modelo neoproductivista por el de desarrollo endógeno es necesario. Lo que obliga a una descentralización sustantiva y está sujeto a un proceso de devolución territorial, lo que permitiría desbloquear el veto de los grandes grupos económicos y la burocracia central. El desarrollo territorial implica la real instrumentalización de planificación territorial vinculante y la generación de recursos vía la temida ley de rentas regionales, negada por la oligarquía económica y financiera de Santiago. Es necesario modificar la lógica de la política pública basada en los sempiternos "planes" de Arauco o Araucanía de alcance limitado, por la implementación de estructuras financieras y de desarrollo estructural que permitan la sustentabilidad de su propio desarrollo socio económico incluyendo la universidad propia, la agricultura sostenible y la promoción de su riqueza comunitaria, cultural y moral, en un país en crisis ética y ambiental.

\section{REFERENCIAS BIBLIOGRÁFICAS}

Albó, X. (2000). Aymaras entre Bolivia, Perú y Chile. Estudios Atacameños, (19), pp 43-73.

Arnstein, S. (1969). A Ladder Of Citizen Participation. Journal of the American Planning Association, 35 (4), pp. 216-224

Aylwin, J., (30 de mayo del 2019), La reforma a la Ley Indígena: un Gobierno que no respeta ni escucha, El Mostrador. Recuperado 
de https://www.elmostrador.cl/destacado/2019/05/30/lareforma-a-la-ley-indigena-un-gobierno-que-no-respeta-niescucha/Bartolomé, M. y Barabas, A. (2004). Recursos culturales y autonomía étnica. La democracia participativa de los Kuna de Panamá, Historia y Memoria, (10), pp. 1-27.

Bastos, S. y Camus, M. (2004). El Movimiento Maya: Una mirada en Perspectiva. Ciudad de Guatemala, Guatemala: FLACSO.

Bengoa, J. (2000). La emergencia indígena en América latina. Santiago, Chile: Fondo de Cultura Económica.

Boitano, A. (2014). Grupos minorizados: formas de identidad, reconocimiento y ciudadania (Tesis Doctorado). Pontificia Universidad Católica. Santiago.

DS No66 (2014), Que Regula el Procedimiento de Consulta Indígena. Chile: BCN

Calduch, R. (1991). Relaciones Internacionales. Madrid, España: Editorial Ediciones Ciencias Sociales UCM.

Canihuan, N. (2015). Trayectorias políticas: historia de vida de alcaldes mapuche. Santiago, Chile: RilEditores.

Cayuqueo, P. (2014). Esa ruca llamada Chile y otras crónicas mapuches. Santiago, Chile: Catalonia.

Conferencia Episcopal. (2017). La Santidad de negociar sin miedo por una región mapuche plurinacional en paz (Documento de Trabajo). Santiago, Chile: Conferencia Episcopal.

Cortez, F. Mariman, J. Molina, R. Valenzuela, E. (2015). Territorios Rebeldes del Siglo XXI: Resurgimiento de la demanda de autonomía territorial. En Valenzuela E. Territorios Rebeldes. Autonomias versus presicracia centralista. Pp. 231-278. Santiago, Chile: Universidad Alberto Hurtado. 
El Dinamo (9 de noviembre de 2018), Auncan Wilcaman avaló “el derecho a rebelión" del pueblo mauche. El Dinamo. Recuperado de https://www.eldinamo.cl/nacional/2018/11/09/aucanhuilcaman-avalo-el-derecho-a-rebelion-del-pueblo-mapuche/

El Mostrador (24 de septiembre de 2018), Empresarios "felices" con Plan Araucanía de Alfredo Moreno. El Mostrador. Recuperado de

https://www.elmostrador.cl/mercados/2018/09/24/empresari os-felices-con-plan-araucania-de-alfredo-moreno/

El Mostrador (24 de mayo de 2019), Movimiento mapuche rechaza consulta indígena y exige justicia por crimen de Catrillanca, El Mostrador. Recuperado de https://www.elmostrador.cl/noticias/pais/2019/05/24/movi miento-mapuche-rechaza-consulta-indigena-y-exige-justiciapor-crimen-de-catrillanca/

Espinoza, C. (2014). Municipio, procesos electorales y etnicidad. Transformaciones en la distribución del poder político municipal en Trinchero H., Campos L. y Valverde S., Pueblos Indigenas, Estados nacionales y fronteras. Buenos Aires, Argentina: UBA.

Espinoza, C. (2016). Ley de borde costero y cuestión étnica en Chile: Del discurso a la práctica política. Universum, 3 (1), pp. 123-139.

Foerster, R. \& Montecino, S., (1988). Organizaciones, Lideres y contiendas mapuche (1900-1970). Santiago, Chile: Ediciones Centros de Estudios de la Mujer.

Fundación Aitue. (2014). Mecanismos de participación política y social de los Pueblos Originarios en asuntos que le son propios. Recuperado de: https://www.fundacionaitue.cl/wpcontent/uploads/2014/12/Estudio Participacion Politica y S ocial Indigena Comparada.pdf. 
García, F. (2018). La relación entre un movimiento social (CONAIE) y un movimiento político (Pachakutik) en cuatro gobiernos locales de la Sierra y Amazonia ecuatoriana. Revista Antropologías del Sur, 5 (9), pp. 113 - 129.

González, J., Valenzuela, E. (2017). Mapa de demandas etnoterritoriales indígenas en Chile: Mapuche-rapanuis-diaguitas rebeldes, aymaras y atacameños consociativos. Revista Iberoamericana de Estudios Municipales, VIII (16), pp. 79-107.

González, T. (15 de enero de 2019). Diputado Mellado por La Araucanía: "La famosa militarización se produjo en el gobierno de Bachelet". Diario Uchile. Recuperado de https:/ / radio.uchile.cl/2019/01/15/diputado-mellado-por-laaraucania-la-famosa-militarizacion-se-produjo-en-el-gobiernode-bachelet/

Gundermann, H., (2003). Sociedades indígenas, municipio y etnicidad: la transformación de los espacios políticos locales andinos en Chile. Estudios Atacameños, (25), pp. 55-77.

Herrera, M. (2019). El fracaso de las autonomías indígenas campesinas en Bolivia (Avance de Tesis de Doctorado). Universidad Alberto Hurtado. Santiago de Chile.

IDERE. (2019). Índice de Desarrollo Regional. Santiago, Chile: ICHEM.

INE. (2017). Resultados Censo 2017. Santiago, Chile. Recuperado de http://resultados.censo2017.cl/

La Tercera (31 de marzo de 2017), Gobierno se querella por Ley de Seguridad Interior contra la CAM, La Tercera. Recuperado de https://www.latercera.com/noticia/gobierno-invocara-leyseguridad-del-estado-la-cam/

Leighton, H. (22 de abril de 2019). Ministro Moreno "tiró la toalla" en Desarrollo Social. El Mostrador. Recuperado en 
https://www.elmostrador.cl/destacado/2019/04/22/ministromoreno-tiro-la-toalla-en-desarrollo-social/

Mahoney, J., (2001) Path-Dependent Explanations of Regime Change: Central America in Comparative Perspective. Estudies in Comparative International Development. (30) Nº1. Pp 111-141.

Marimán, J. (2012). Autodeterminación: Ideas políticas mapuche en los albores del siglo XXI. Santiago, Chile: Lom Editores.

Mella, M. (2018). El Reclamo de la Mirada, etnografía transvalorativa en la lucha por el reconocimiento mapuche: Municipio de Saavedra, ministerio de salud y forestal Mininco. (Tesis Doctoral) Universidad de Barcelona. Barcelona España.

Ministerio de Desarrollo Social. (2017). Informe Final Proceso Participativo Constituyente Indígena. Santiago, Chile. Recuperado de http://archivospresidenciales.archivonacional.cl/uploads/r/nul 1/0/1/b/01b50c3f321987047f9683dcd25c7012bf38473fa0eb0e 012ef868e49f8668b7/ home aristoteles documentos PC CC O DT 37.pdf

Morcillo, L. (2013). ¿Quién dijo que estamos cansados de ser indios? Kuna Yala: territorio y turismo". Ensayo de Cooperación Internacional para el Desarrollo 5: Santander, España. Pp. 3-32.

PNUD. (2015). Representación Indigena en poderes legislativos. Santiago, Chile: PNUD.

Segura, P. (2017). Sintesis de propuestas de partidos regionalistas. Santiago, Chile: H. Boll.

Telesur (27 de septiembre de 2018), Mapuches chilenos marcha en rechazo al Plan Araucanía. Recuperado de https://www.telesurtv.net/news/mapuches-chilenos-rechazoplan-araucania-20180927-0090.html

Valenzuela, E. (6 de septiembre de 2018). Ministro Moreno: ¿el patrón del bien o del mal?. El Mostrador. Recuperado de 
https://www.elmostrador.cl/noticias/opinion/columnas/2018 /09/06/ministro-moreno-el-patron-del-bien-o-del-mal/

Velásquez, E. (19 de julio de 2018). Bancada Regionalista promueve Universidades Indígenas. Recuperado de https://www.elmostrador.cl/dia/2018/07/19/bancadaregionalista-presento-proyecto-que-impulsa-creacion-deuniversidades-indigenas-interculturales /

Werken (21 de octubre de 2019), Coordinadora Arauco Malleco llama a las comunidades Mapuches a un levantamiento más fuerte por las reivindicaciones territoriales, Werken.cl. Recuperado de http://werken.cl/coordinadora-arauco-malleco-llama-a-lascomunidades-mapuches-a-un-levantamiento-mas-fuerte-porlas-reivindicaciones-territoriales/

Zamorano C. (22 de diciembre de 2018), Convocan Movilización Nacional Mapuche antes de fin de año. La Tercera. Recuperado de https://www.latercera.com/nacional/noticia/convocanmovilizacion-nacional-mapuche-fin-ano/458176/. 